\title{
COLUMN PACKINGS FOR GAS CHROMATOGRAPHY
}

$\mathrm{T}$ HE second in the series of informal symposia organized by the Gas Chromatography Discussion Group associated with the Institute of Petroleum was held in the Organic Chemistry Laboratory, Cambridge, on October 4. More than two hundred participants attended and four papers were presented. Local organization was carried out by Dr. J. H. Purnell.

After a short welcoming address by Prof. R. G. W. Norrish, Dr. A. T. James, chairman of the Discussion Group, outlined a new organization for the Group which it is hoped to put into effect shortly. This would allow a definite membership open to all workers in the field, and many of those present indicated their interest in the scheme. He also directed attention to the Second International Symposium on Gas Chromatography being arranged by the Group in Amsterdam during May.

Dr. J. J. van Deemter presented an introductory paper on column packings and peak sharpness. He considered the factors contributing to peak broadening in the light of current theories of gas chromatography and discussed the effects of gas velocity, sample size, support particle size and stationary phase proportion, on column efficiency. After considering the latest form of the van Deemter equation, relating the height equivalent to a theoretical plate (HETP) and diffusional effects, he pointed out that a variation in film thickness on the packing would also lead to peak broadening. This effect is probably particularly significant when low proportions of stationary phase are employed. An interesting observation was the fact that resistance to mass transfer in the liquid phase was not, in all cases, dependent on the viscosity of the stationary phase. With silicone oils, variation of viscosity over a hundredfold range had little effect on column efficiency. Dr. A. J. P. Martin suggested that with linear polymers increasing chain length has little effect on the diffusivity of small molecules.

Mr. R. P. W. Scott then presented a paper describing an experimental investigation of many of the parameters determining column efficiency considered by the previous speaker. The hydrogen flame detector had been employed with a mixture of 75 per cent hydrogen plus 25 per cent nitrogen as carrier gas and a single stationary phase Apiezon Oil $A$ supported on Johns-Manville $C 22$ insulating brick. An examination of columns prepared from brick powders of different particle size with a constant proportion (20 per cent weight) of stationary phase at $78^{\circ} \mathrm{C}$. had shown, as would be predicted by the van Deemter theory, that the smaller particles are more effective. In addition, the importance of a narrow particle size distribution was demonstrated. The best stationary phase/support ratio for short columns a few feet long was found to be 20 per cent $w / w$, but theoretical plates values above about 3,000 were best obtained by the use of long columns with low proportions of stationary phase, that is, 5 per cent $\mathrm{w} / \mathrm{w}$ and below. Data were given for a $25-\mathrm{ft}$. column having an efficiency of $10,000-12,000$ theoretical plates which would partially resolve para- and meta-xylenes on a volatility basis.

The afternoon session opened with a paper by $\mathrm{Mr}$. C. S. G. Phillips on the use of metal salts as column liquids. Copper and zinc stearates and nickel oleate had been examined, the stearates at $156^{\circ} \mathrm{C}$. and the nickel salt at $97^{\circ} \mathrm{C}$. Although with hydrocarbons and other non-polar compounds separations were similar to that obtained with conventional stationary phase liquids, with amines, for example, strong co-ordination forces to the metal atoms produced new types of separations markedly dependent on steric factors. Several thousandfold differences in retention times could be obtained in favourable cases. Mr. Phillips cited the case of the separation of 2,6 -Iutidene and $\alpha-, \beta$ - and $\gamma$-picolines. About two hundred thousand plates were required to separate these compounds, using only their volatility differences, but with zinc stearate at $150^{\circ} \mathrm{C}$. less than five plates are sufficient. The results with these metal-salt columns could be related to studies of complex-ion formation in aqueous solutions and provide information on complexing equilibria.

In the last paper Dr. J. H. Purnell put forward, on behalf of the Gas Chromatography Discussion Group, further recommendations ${ }^{1}$ concerning the presentation of gas-liquid chromatographic retention data. It was proposed that retention data be presented in one of the two following ways, each being adequate provided any additional information required for interconversion is also given.

(1) In tables of relative retention times for at least two temperatures (so far as is precticable) with, where possible, the partition coefficient or specific retention volume of the standard solute. A suitable graphical method is the plot of logarithm of relative retention times versus the reciprocal of the absolute temperature.

(2) In terms of a linear equation relating the parameter chosen to temperature, for example, by an Antoine equation

$$
\log V_{g}^{0}=A /(t+C)+B
$$

where $t=$ temperature in deg. C. and $A, B$ and $C$ are constants. This may be done graphically, but where results are numerous and the line represents the experimental results with accuracy, the constants of the equation (with the temperature limits between which it has been found to hold) will allow calculation or replotting on a large scale. It is hoped that the detailed recommendations will be published shortly in Analytical Chemistry.

Before the meeting closed, the chairman asked Mr. McWilliams, a visitor from Australia, to describe briefly a new detector he had mentioned earlier in the proceedings. This employed a small flame at the exit from the column, as in the detector developed by R. P. W. Scott, but instead of flame temperature, the ionization current between the jet and a positive platinum-gauze electrode inserted in the flame was measured. Large changes in current occur on introducing vapour into the nitrogen/hydrogen mixture feeding the flame, and a detection limit of 1 part in $4 \times 10^{8} \mathrm{v} / \mathrm{v}$ was claimed. The sensitivity in the units proposed at the last moeting ${ }^{2}$ was given as $3 \times 10^{7}$ $\mathrm{mV} . \mathrm{ml} . / \mathrm{mgm}$. with a noise-level of $0.2 \mathrm{mV}$.

D. H. Desty 